\title{
First record of Latrodectus dahli Levi, 1959 (Araneae: Theridiidae) from Iraq
}

\author{
Shurooq Abdullah Najim ${ }^{\text {1* }}$ and Kadhim Salih AL-Hadlag ${ }^{2}$ \\ ${ }^{1}$ Natural History Museum, Basrah University, Basrah, Iraq \\ ${ }^{2}$ Biology Department, Science College, Basrah University, Basrah, Iraq \\ *Corresponding author ${ }^{\circledR}$ : shurooq.najim@uobasrah.edu.iq
}

Received: 11 April 2020

Accepted: 23 May 2020

Published online: 4 June 2020

\begin{abstract}
The widow spider Latrodectus dahli Levi, 1959 is recorded for the first time from Iraq, based on four female specimens collected in Basra Province. There are 32 valid species of the genus Latrodectus with a worldwide distribution. The female copulatory organ is illustrated. Latrodectus dahli is similar to L. hystrix Simon, 1890 in the female internal duct system but differs in the shape and coloration of the opisthosoma. Distribution records now include North Africa, Turkey, Azerbaijan, Kazakhstan, Iran, Central Asia (WSC, 2020), and now Iraq.
\end{abstract}

Key words: Medically-important, widow spider, Basra

\section{Introduction}

The genus Latrodectus Walckenaer, 1805 (Theridiidae) includes species commonly known as widow spiders, infamous for their highly neurotoxic venom (Ushkaryov et al., 2004). Currently, there are 32 valid species of this group known from around the world (WSC, 2020).

The medical syndrome that be caused as a result of their bites is known as "Latrodectism" which can result in a variety of symptoms, including the rigidness of stomach muscles, sweating, aches, local pain and in some rare cases, death (Foelix, 2010). Although the females are responsible for almost all latrodectism cases and the smaller males are unable to cause human envenomation, some cases have been reported where the male's bite has been able to cause such symptoms (Isbister and Gray, 2003).

Knoflach and van Harten (2002) provided an excellent revision of the taxonomy, distribution and the biology of the genus Latrodectus in the Arabian Peninsula. This genus has previously been recorded from Iran, by Mirshamsi Kakhki (2005) in the form of Latrodectus tredecimguttatus (Rossi, 1790), L. pallidus Pickard-Cambridge, 1872 and L. dahli Levi, 1959. Also, Rafinejad et al. (2007) recorded these species as well as L. geometricus Koch, 1841 from Khorasan Province, Iran. Zamani et al. (2014) recorded five species from Iran, including L. cinctus Blackwall, 1865, L. dahli, L. geometricus, L. pallidus, and L. tredecimguttatus. The first species was a new country record and other species were new records for some Iranian provinces. Jäger and Gromov (2011) recorded Latrodectus dahli for the first time from Morocco, Turkey, Turkmenistan and the United Arab Emirates. 
However, the araneological studies of Iraq are still poor, as the first checklist of Iraqi araneofauna was completed by Zamani and El-Hennawy (2016), and they recorded 32 species belonging to 29 genera and 16 families from Iraq. After that, Fomichev et al. (2018), based on new materials from northern Iraq added 20 new species for the country in 13 genera and six new families, as well as description of a new species. They therefore upgraded the Iraqi araneofauna to 54 species. In the same year, members of two additional families, namely Agelenidae and Pholcidae were added to the Iraqi spider fauna by Al-Khazali (2018) and AlKhazali and Najim (2018), respectively.

There are 32 valid species of the genus Latrodectus with a worldwide distribution (WSC, 2020). Thus, the aim of the present study is to increase the knowledge of the Iraqi spider fauna, by providing data on $L$. dahli as the first country record.

\section{Material and Methods}

The specimens were collected by hand during January to December 2019.

Four female specimens were collected from Al-Rumaila, Al-Shamalia site $\left(30^{\circ} 33.540^{`} \mathrm{~N}\right.$, $047^{\circ} 10.259^{\circ} \mathrm{E}$ ) (Fig. 1). The collection site is a desert region dominated by sand-dunes and annual desert plants such as Stipa tortelis and some perennial plants, Haloxylon spp., Lycium barbarum and Prosopis farcta (Fig. 2).

The collected specimens were preserved in $80 \%$ ethanol and deposited in the Natural History Museum of Basrah University (NHMBU), Iraq. The specimens were studied and examined by dissecting microscope (LEICA EZ 4HD), using the identification key provided by Knoflach and van Harten (2002).

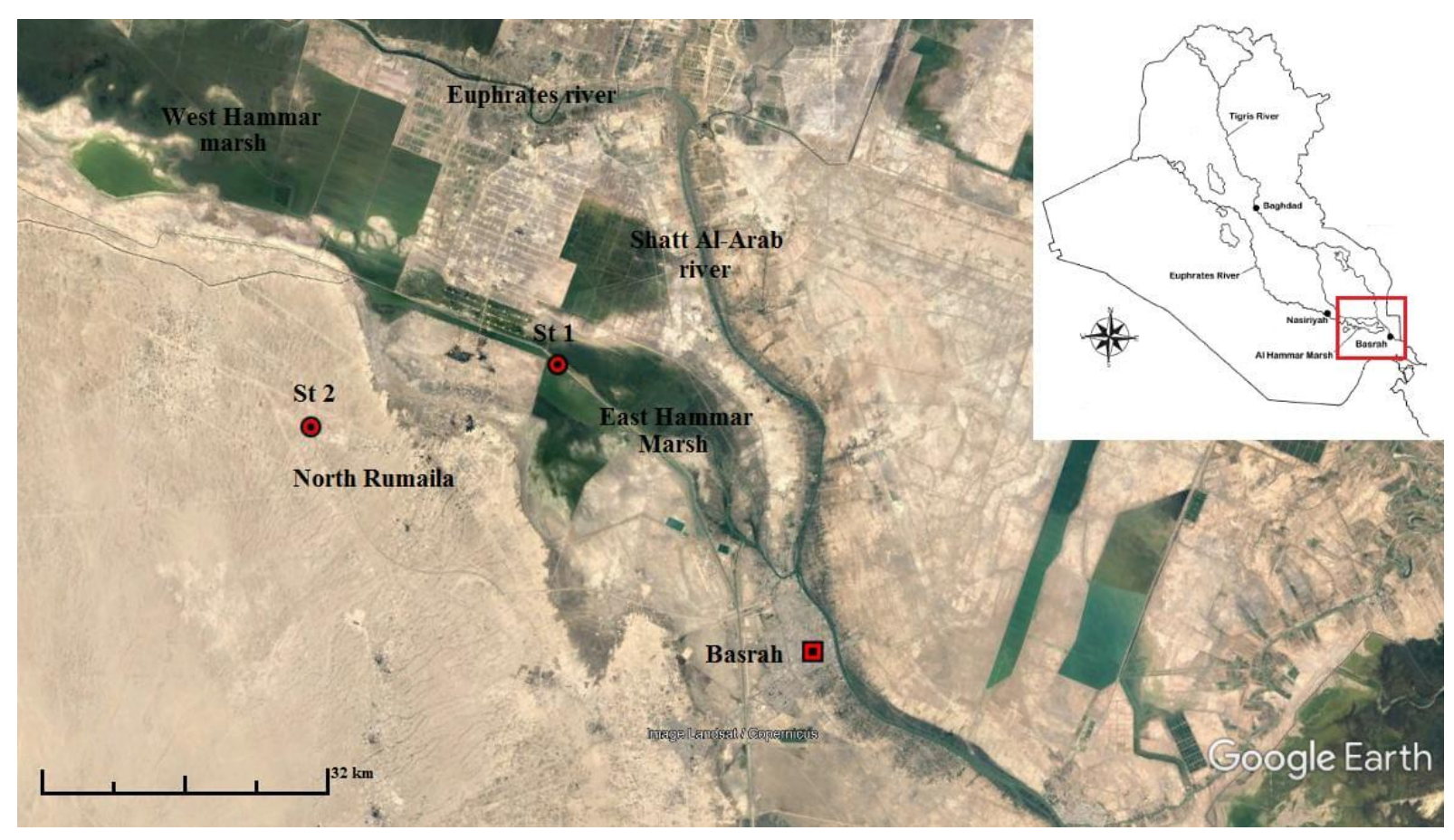

Figure 1: Map of collecting locality area of Latrodectus dahli, Levi, 1959 from Al-Rumaila, Al-Shamalia site, Basra, Iraq. 


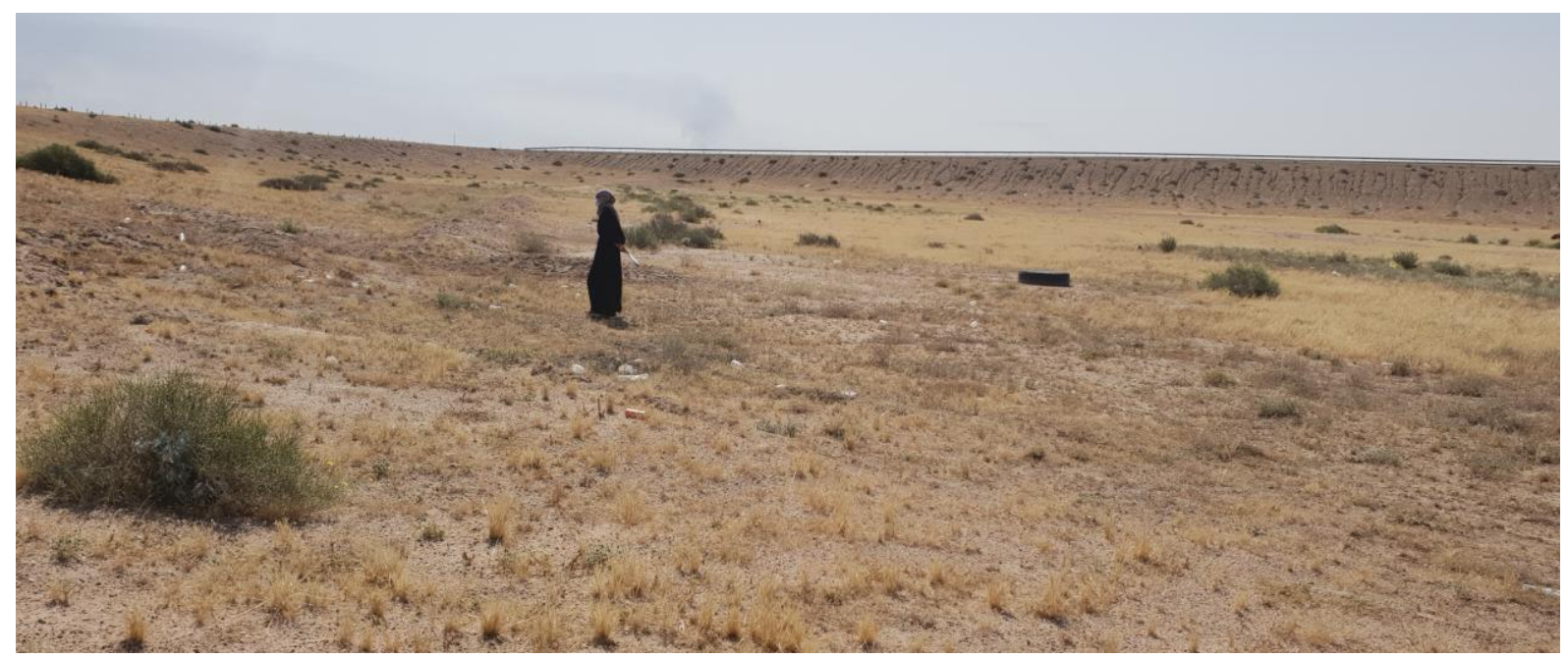

Figure 2: The habitat of Latrodectus dahli Levi, 1959 in Al-Rumaila, Al-Shamalia, Basra, Iraq.

\section{Results and Discussion}

The spiders build their scaffold webs between rocks, usually close to the ground, and most specimens had egg sacs in their webs (Fig. 3).

\section{Latrodectus dahli Levi, 1959}

\section{Morphology}

Male: Not recorded.

Female: Total body length 11-13 mm, prosoma black and abdomen black, legs lighter than the body, spermathecal ducts with one coil, abdomen provided with many long and short setae (Fig. 4A-D).

Latrodectus dahli is similar to L. hystrix Simon, 1890 in the female internal duct system but differs in the shape and coloration of the opisthosoma (Knoflach and van Harten, 2002: pl. 49-52).

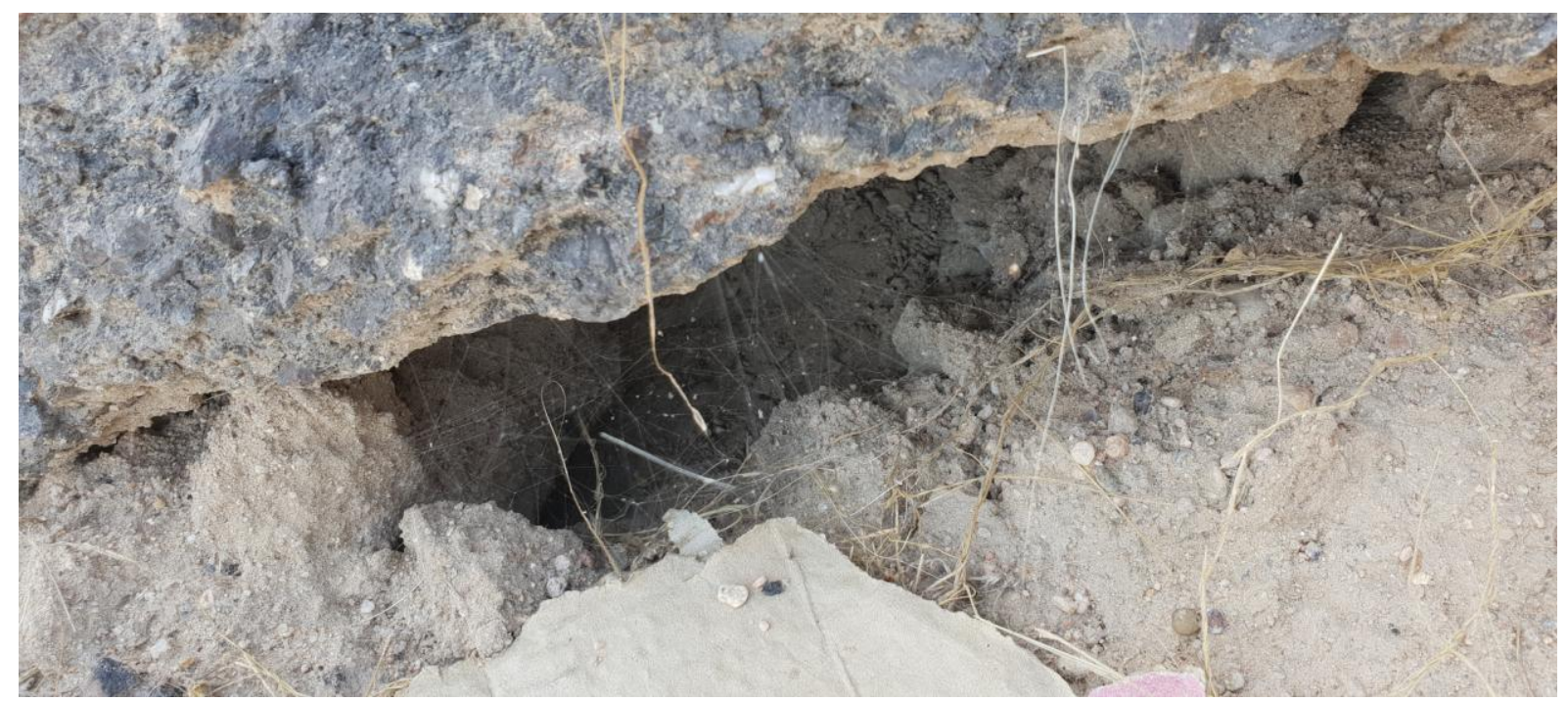

Figure 3: The habitat of Latrodectus dahli Levi, 1959 with its scaffold web, from AlRumaila, Al-Shamalia, Basrah, Iraq. 


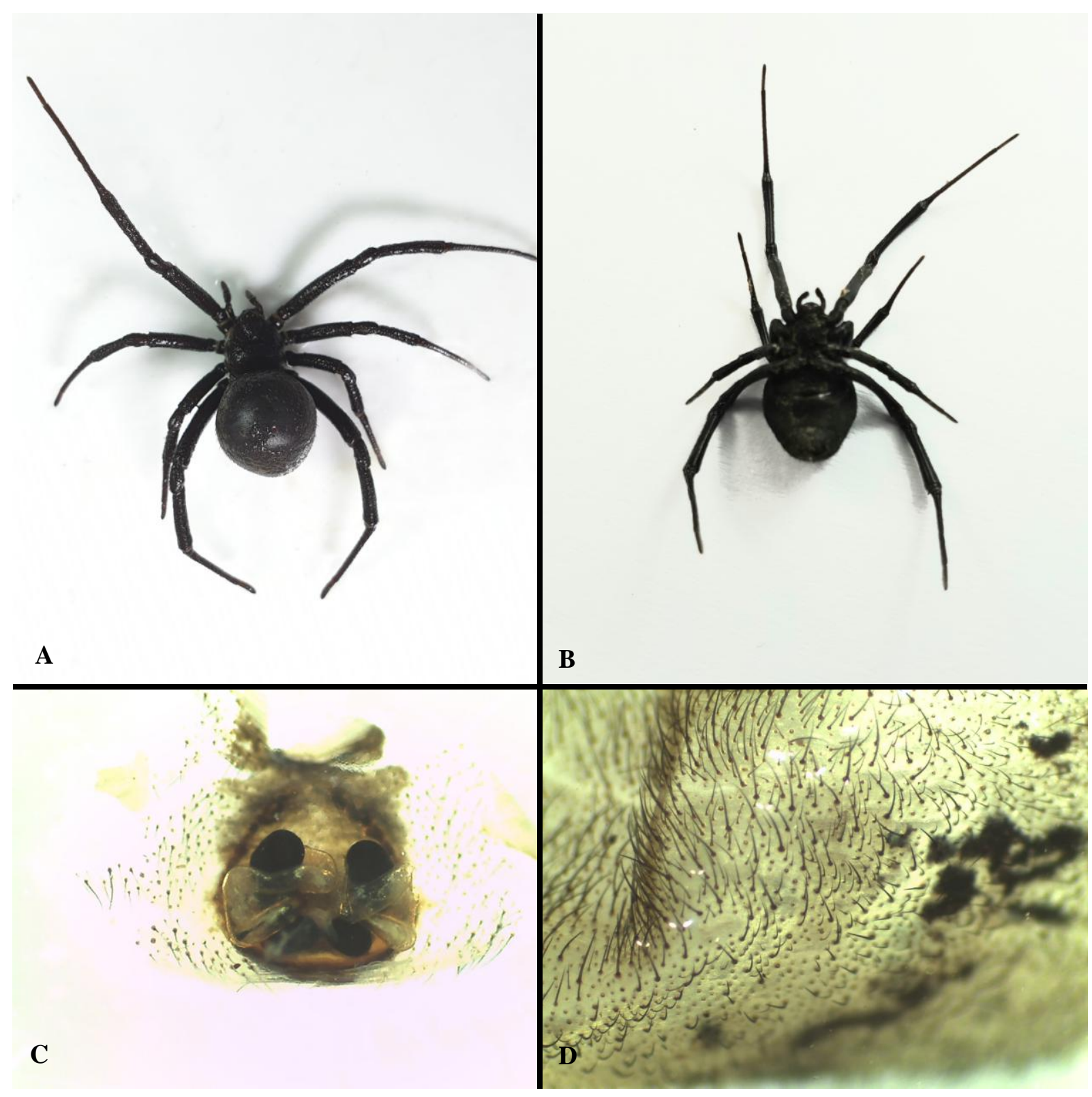

Figure 4: Latrodectus dahli Levi, 1959, from southern Iraq. Habitus of female, dorsal view (A), ventral view (B), vulva, dorsal view (C), and long and short setae on abdomen (D).

\section{Distribution}

North Africa, Turkey, Azerbaijan, Kazakhstan, Iran, Central Asia (WSC, 2020), Iraq (first record).

\section{Comments}

This genus can be differentiated from the other genera in the family Theridiidae, by a large colulus, chelicerae with no teeth, separated lateral eyes, characteristic genitalia, the carapace is pear shaped, abdomen is globular with shiny appearance, orange to red markings are usually visible on the abdomen, dorsally, ventrally or both, and the female internal genitalia with dumb-bell shaped seminal receptacles and coiled connecting duct (Lotz, 1994).

The females of $L$. dahli can be distinguished from other congeners by their completely black body coloration, with only the tibia and tarsi a little lighter, abdomen having many short and long setae (Knoflach and van Harten, 2002). 
Females of $L$. dahli are similar to females of $L$. hystrix in their internal duct system, as in both species the copulatory ducts enter the receptacula after one coil, but they are wider than those of $L$. hystrix. They can also be distinguished by the coloration of the abdomen which is dark with many light spots in L. hystrix and the setation pattern having many short spines on the abdomen but no long setae (Levi, 1959).

Latrodectus dahli was previously recorded from many countries, with some of them sharing a common border with Iraq. It has been recorded from Turkey (Jäger and Gromov, 2011), as well as different provinces of Iran, including Bushehr (Levi, 1959), Khorasan (Mirshamsi Kakhki, 2005; Rafinejad et al., 2007), Hormozgan (Zamani et al., 2014), Fars (Jäger and Gromov, 2011) and East Azerbaijan (Rahmani et al., 2014); and so it may be widely distributed across Iraqi provinces and other neighboring countries.

Further, intensive, sampling efforts and research into the Latrodectus fauna of Iraq is needed to help develop a comprehensive study of this medically important genus.

\section{Acknowledgments}

The paper benefited from the criticism and suggestions of Alireza Zamani (University of Turku, Finland), and two anonymous referees, and to whom we express our deep gratitude.

\section{References}

Al-Khazali, A. M (2018). The first record of family Agelenidae from Iraq (Arachnida: Araneae). Serket, 16 (2): 60-65.

Al-Khazali, A. M. and Najim, S. A. (2018). First record of Pholcidae (Arachnida: Araneae) from Iraq. Bulletin of Iraq Natural History Museum, 15 (2): 179-187.

Foelix, R. (2010). Biology of spiders. Third Edition. Oxford University Press, Oxford. 432 pp.

Fomichev, A. A., Marusik, Y. M. and Koponen, S. (2018). New data on spiders (Arachnida: Araneae) of Iraq. Zoology in the Middle East, 64 (4): 329-339. https://doi.org/10.1080/09397140.2018.1484018

Isbister, G. K. and Gray, M. R. (2003). Latrodectism: a prospective cohort study of bites by formally identified redback spiders. The Medical Journal of Australia, 179 (2): 88-91. https://doi.org/10.56941j.1326-5377.tb05641.x

Jäger, P. and Gromov, A. V. (2011). First Records of Latrodectus dahli Levi, 1959 from Morocco, Turkey, Turkmenistan and the United Arab Emirates. Arachnology, 15 (6): 188-192. https://doi.org/10.13156/arac.2011.15.6.188

Knoflach, B. and Harten, A. van. (2002). The genus Latrodectus (Araneae: Theridiidae) from mainland Yemen, the Socotra Archipelago and adjacent countries. Fauna of Arabia, 19: 321-361.

Levi, H. W. (1959). The spider genus Latrodectus (Araneae: Theridiidae). Transactions of the American Microscopical Society, 78 (1): 7-43.

Lotz, L. N. (1994). The button spiders of southern Africa (Latrodectus: Araneae: Theridiidae). Spider Club News, 9 (3): 9-16.

Mirshamsi Kakhki, O. (2005). New records of three Latrodectus species found in Khorasan province (Araneae: Theridiidae). Iranian Journal of Animal Biosystematics (IJAB), 1 (1): $52-58$.

Platnick, N. I. (2010). The World Spider Catalog. American Museum of Natural History. Version 11.0, online at http//:research.amnh.org/iz/spiders/catalog. 
Rafinejad, J., Tirgari, S., Biglarian, F. and Shemshad, K. H. (2007). Systematics, bioecology, and medical importance of widow spiders (Latrodectus spp.) in Khorasan Province, Iran. Iranian Journal of Arthropod-Borne Diseases, 1 (1): 52-57.

Rahmani, F., Banan Khojasteh, S. M., Ebrahimi Bakhtavar, H., Shahsavari Nia, K., Jafari Roohi, A., Massoud, A., Najafi Fakhrayi, B. and Shahbazi, S. (2014). Identification of widow spiders in East Azerbaijan, Iran: case series. Medical Journal of Tabriz University of Medical Sciences and Health Services, 36 (1): 82-86.

Ushkaryov, Y. A., Volynski, K. E. and Ashton, A. C. (2004). The multiple actions of black widow spider toxins and their selective use in neurosecretion studies. Toxicon, 43 (5): 527-542. https://doi.org/10.1016/j.toxicon.2004.02.008

WSC (World Spider Catalog) (2020). World Spider Catalog. Version 21.0. Natural History Museum Bern. http://wsc.nmbe.ch (Accessed on 23 May 2020). https://doi.org $/ 10.24436 / 2$

Zamani, A. and El-Hennawy, H. K. (2016). Preliminary list of the spiders of Iraq (Arachnida: Araneae). Arachnida - Rivista Aracnologica Italiana, 6: 12-20.

Zamani, A., Mirshamsi, O., Savoji, A. and Shahi, M. (2014). Contribution to the distribution of spiders with significant medical importance (Araneae: Loxosceles and Latrodectus) in Iran, with a new record for the country. Iranian Journal of Animal Biosystematics (IJAB), 10 (1): 57-66. 